\title{
Impact of maternal diabetes on birthweight is greater in non-Hispanic blacks than in non-Hispanic whites
}

\author{
K. J. Hunt • N. M. Marlow • M. Gebregziabher • \\ C. N. Ellerbe • J. Mauldin • M. E. Mayorga • J. E. Korte
}

Received: 15 September 2011 / Accepted: 2 December 2011 /Published online: 12 January 2012

(C) Springer-Verlag 2012

\begin{abstract}
Aims/hypothesis To determine the impact of maternal diabetes during pregnancy on racial disparities in fetal growth.

Methods Using linked birth certificate, inpatient hospital and prenatal claims data we examined live singleton births of mothers resident in South Carolina who self-reported their race as non-Hispanic white (NHW; $n=140,128)$ or nonHispanic black (NHB; $n=82,492)$ and delivered at $28-$ 42 weeks' gestation between 2004 and 2008.

Results Prepregnancy diabetes prevalence was higher in NHB (3.0\%) than in NHW $(1.7 \%)$, while the prevalence of gestational diabetes mellitus (GDM) was similar in NHB (6.1\%) and NHW (6.3\%). At a delivery BMI of $35 \mathrm{~kg} / \mathrm{m}^{2}$, GDM exposure was associated with an average birthweight only $17 \mathrm{~g}(95 \% \mathrm{CI} 4,30)$ higher in NHW, but $78 \mathrm{~g} \mathrm{(95 \%} \mathrm{CI} \mathrm{61,}$ 95 ) higher in NHB (controlling for gestational age, maternal age, infant sex and availability of information on prenatal care). Figures for prepregnancy diabetes were $58 \mathrm{~g}(95 \% \mathrm{CI} 34,81)$ in NHW and $60 \mathrm{~g}(95 \%$ CI 37,84$)$ in NHB. GDM had a greater impact on birthweight in NHB than in NHW (60 g racial difference [95\% CI 39, 82]), while prepregnancy diabetes had
\end{abstract}

\footnotetext{
K. J. Hunt $(\bowtie) \cdot$ N. M. Marlow $\cdot$ M. Gebregziabher

C. N. Ellerbe · J. E. Korte

Department of Medicine/Biostatistics and Epidemiology,

Medical University of South Carolina,

135 Cannon Street, Suite 302, P.O. Box 250835,

Charleston, SC 29425, USA

e-mail: huntke@musc.edu

J. Mauldin

Department of Obstetrics and Gynecology,

Medical University of South Carolina,

Charleston, SC, USA

M. E. Mayorga

Department of Industrial Engineering, Clemson University,

Clemson, SC, USA
}

a large but similar impact. Similarly, the RR for GDM of having a large- relative to a normal-weight-for-gestational-age infant was lower in NHW (RR 1.41 [95\% CI 1.34, 1.49]) than in NHB (RR 2.24 [95\% CI 2.05, 2.46]).

Conclusions/interpretation These data suggest that the negative effects of GDM combined with obesity during pregnancy may be greater in NHB than in NHW individuals.

Keywords Birthweight · Diabetes · Gestational diabetes mellitus · Non-Hispanic black · Non-Hispanic white .

Pregnancy Prepregnancy diabetes
Abbreviations
GDM Gestational diabetes mellitus
LGA Large for gestational age
LMP Last menstrual period
NGA Normal weight for gestational age
NHB Non-Hispanic black
NHW Non-Hispanic white
SGA Small for gestational age

\section{Introduction}

As the incidence of diabetes continues to rise, women of childbearing age are at increased risk of diabetes during pregnancy [1-7]. The lifetime risk of diabetes among females born in the United States in 2000 was estimated to be $39 \%$, based on information obtained from the National Health and Nutrition Examination Surveys (NHANES) conducted between 1984 and 2000 [8]. Moreover, the estimated lifetime risk of diabetes was higher for minority groups than for non-Hispanic whites (NHW) and for women compared with men [8].

The 'fetal origin of disease' hypothesis proposes that gestational programming may critically influence adult health and 
disease [9]. Obesity prior to pregnancy and high weight gain during pregnancy predispose women to gestational diabetes mellitus (GDM) and early-onset type 2 diabetes [10-12]. Maternal diabetes during gestation exposes the fetus to hyperglycaemia, resulting in increased fetal insulin levels that both promote the storage of excess energy as fat and act as a growth factor. Maternal diabetes is associated with high birthweight, increased childhood and adult obesity and increased risk of type 2 diabetes [13-17]. Children exposed in utero to diabetes are at higher risk of obesity and diabetes compared with their unexposed siblings, suggesting that the increased risk to the exposed offspring is not exclusively genetic [18, 19].

Maternal obesity, pregnancy weight gain and diabetes during pregnancy are modifiable risk factors that determine birthweight for gestational age during the third trimester. Macrosomic infants, large-for-gestational-age (LGA) infants and infants exposed to diabetes in utero are at increased risk of complications during delivery [20, 21]. While differences in maternal and neonatal outcomes in blacks and whites have been examined at the low end of the birthweight distribution [22-24], few studies have focused on racial/ethnic differences in neonatal outcomes at the high end of the birthweight distribution. In a study based on US live birth data from 1990 to 1991, Kieffer et al. reported a disparity in birthweight associated with diabetes of $212 \mathrm{~g}$ in black infants, but only $116 \mathrm{~g}$ in white infants [25]. However, this study was limited in that it relied solely on birth certificatereported presence of diabetes during pregnancy at a time when diabetes was less frequently reported on the birth certificate, and no information on maternal prepregnancy weight or weight gain during pregnancy was available. Therefore, our objective was to determine the impact of maternal diabetes during pregnancy on racial disparities in birthweight for gestational age at the population level in South Carolina in 2004 to 2008 .

\section{Methods}

Study design and population Live singleton births of mothers resident in South Carolina who self-reported their race as NHW or non-Hispanic black (NHB), and who delivered at a gestational age of 28-42 weeks between January 2004 and December 2008, comprise this population-based cohort study. Birth certificate information was obtained from the South Carolina Department of Health and Environmental Control and linked by the South Carolina Office of Research and Statistics to inpatient hospital discharge records for the state to obtain maternal inpatient procedure and diagnostic codes pertaining to delivery. Additionally, outpatient diagnostic codes were available for the prenatal period for mothers who received prenatal care through either Medicaid or the South Carolina State Health Plan (i.e. a private health insurance plan for state employees). The linkage between databases is based on an algorithm developed by the South Carolina Office of Research and Statistics and relies on personal identifying information. The Institutional Review Board of the Medical University of South Carolina approved the study.

Variable definition Diabetes during pregnancy was defined either by gestational or prepregnancy diabetes reported on the birth certificate or if it was coded for on the inpatient hospital discharge records or during the prenatal period. The prenatal period was defined by the date of delivery and gestational age of the infant at delivery and additionally included the year prior to conception in defining prepregnancy diabetes. In addition, for a diagnosis of diabetes during pregnancy based on the prenatal data alone, two or more ICD-9-CM diagnostic codes indicative of diabetes were required in the medical record (www.icd9data.com/2007/ Volume1/240-279/250-259/250/default.htm). This criterion was based on a validated algorithm developed for use in the Veterans Health Administration [26]. Primary and secondary inpatient hospital and prenatal ICD-9-CM diagnosis codes used to define diabetes included those for prepregnancy and GDM (i.e. 64801-64802, 25000-25092, 64881-64882). Further classification into having prepregnancy diabetes or GDM was based on evidence of prepregnancy diabetes from any source. Hence, when one source reported prepregnancy diabetes and another reported GDM a woman was classified as having prepregnancy diabetes. Maternal hypertension during pregnancy was defined as reported on the birth certificate (i.e. either GDM or prepregnancy diabetes).

Maternal race, education (dichotomised on the basis of high school graduation or a General Educational Development Diploma), private health insurance status, firstborn (based on report of previous live births) and tobacco use were defined as reported on the birth certificate. Adequacy of prenatal care was defined based on the revised GINDEX, which combines information from the birth certificate on the trimester when prenatal care was first received and the total number of prenatal visits [27]. Birthweights inconsistent with gestational age were identified based on a modified version of the criteria published by Alexander et al. [28]: the modification allowed for a birthweight up to $6,500 \mathrm{~g}$ at a gestational age of 39 weeks and 7,000 $\mathrm{g}$ at a gestational age $\geq 40$ weeks. Birthweights considered consistent with gestational age are as follows: 28 weeks, $250-2,500 \mathrm{~g} ; 29$ weeks, 250-2,750 g; 30 weeks, 375-3,000 g; 31 weeks, 375-3,250 g; 32 weeks, 500-3,500 g; 33 weeks, 500-3,750 g; 34 weeks, 750-4,000 g; 35 weeks, 750-4,500 g; 36 weeks, 750-5,000 g; 37 weeks, $1,000-5,500 \mathrm{~g} ; 38$ weeks, $1,000-6,000 \mathrm{~g} ; 39$ weeks, $1,000-6,500 \mathrm{~g} ; 40$ weeks, 1,000-7,000 g; 41 weeks, 1,0007,000 g; and 42 weeks, 1,000-7,000 g.

We conducted analyses of birthweight adjusted for gestational age, representing a measure of fetal growth on a 
continuous scale. LGA and small-for-gestational-age (SGA) infants were based on the 90th and 10th percentiles of weight for gestational age, respectively, according to fetal growth curves derived using a United States national reference based on births in 1999-2000 [29]. The same standard growth curve was used for NHW and NHB infants to define LGA and SGA.

Statistical analysis A series of analyses was completed with maternal race, diabetes status and maternal BMI at delivery being the exposures of interest and birthweight being the outcome of interest. Throughout all analyses gestational age and infant sex were covariates in the models; hence, birthweight was adjusted for gestational age and infant sex and was therefore a measure of fetal growth.

Linear regression using up to fourth-order polynomials when required was used to examine the relationship between race, diabetes status and birthweight. Appropriate interaction terms were used to determine whether GDM and prepregnancy diabetes impacted birthweight similarly in NHW and NHB women. In secondary analyses, we also considered gestational age as an effect modifier of the relationship between maternal diabetes and birthweight, and we considered maternal BMI at delivery as a potential effect modifier of the relationship between each type of maternal diabetes and birthweight. A $p$ value of 0.05 was used as a nominal value for statistically significant interactions. Additionally, we used negative-binomial regression to estimate RRs in the framework of generalised linear models [30]. To deal with convergence problems we used Poisson regression with a robust variance estimator [31] as demonstrated by Spiegelman and Hertzmark [32]. Throughout these analyses appropriate interaction terms were used to determine whether race modified the effect of each type of maternal diabetes on dichotomous outcomes of interest including SGA and LGA. Sequentially built models were compared using Akaike's information criterion and the Bayesian information criterion.

\section{Results}

Of 278,438 live singleton births to mothers resident in South Carolina, reasons for exclusion included maternal race or ethnicity missing or unknown, $1,585(0.57 \%)$; maternal race identified as other, $6,032(2.17 \%)$; and maternal race identified as Hispanic, 26,631 (9.56\%). Of the remaining 92,233 births to NHB mothers and 151,957 births to NHW mothers, reasons for exclusion included missing gestational age based on last menstrual period (LMP), 15,541 (6.36\%); gestational age $>42$ weeks, 7,666 (3.14\%); gestational age $<28$ weeks, 2,554 (1.05\%); and birthweights inconsistent with gestational age, $1,254(0.51 \%)$ [28]. Hence, the study population for this analysis includes 80,480 births to NHB mothers and 136,695 births to NHW mothers. Maternal inpatient hospital procedure and diagnostic codes from delivery were successfully linked for 203,699 (93.79\%) births, while prenatal information was available for $114,684(52.81 \%)$ births to mothers with Medicaid and 14,304 (6.59\%) births to mothers with the State Health Plan.

The unadjusted prevalence of prepregnancy diabetes was higher in NHB $(3.0 \%)$ than in NHW $(1.7 \%)$, while the prevalence of GDM was similar in NHB (6.1\%) and NHW (6.3\%; Table 1). On average, maternal age was lower in NHB than in NHW, but higher in those with either prepregnancy diabetes or GDM than in those without diabetes. Mean prepregnancy BMI in NHB ranged from $28.4 \mathrm{~kg} / \mathrm{m}^{2}$ in women without diabetes to $34.7 \mathrm{~kg} / \mathrm{m}^{2}$ in women with prepregnancy diabetes. Respective numbers in NHW women were 25.8 and $31.0 \mathrm{~kg} / \mathrm{m}^{2}$.

Examining the relationship between gestational age and birthweight in the six strata defined by race and diabetes status, we found that infant birthweight was significantly higher in women with GDM than in women without diabetes from a gestational age of 35 through 40 weeks in NHW women and from a gestational age of 35 through 42 weeks in NHB women (Fig. 1a, b). Similarly, infant birthweight was significantly higher in women with prepregnancy diabetes than in women without diabetes from a gestational age of 35 through 39 weeks in NHW women and 34 through 42 weeks in NHB women. Moreover, from a gestational age of 36 weeks through 42 weeks, when over $85 \%$ of births occur, the impact of GDM on birthweight was higher in NHB than in NHW. By contrast, the impact of prepregnancy diabetes on birthweight was only higher in NHB than in NHW from a gestational age of 40 through 42 weeks. For example, at 38 weeks, exposure to GDM in utero was associated on average with birthweights $97 \mathrm{~g}(95 \% \mathrm{CI} 84,109)$ higher in NHW and $157 \mathrm{~g}(95 \% \mathrm{CI}$ $141,174)$ higher in NHB after controlling for maternal age, infant sex and whether information from the mother's prenatal medical record was available (Table 2, Model 1). Parallel numbers for prepregnancy diabetes were $183 \mathrm{~g}(95 \% \mathrm{CI}$ $160,205)$ in NHW and $185 \mathrm{~g}(95 \%$ CI 162,208$)$ in NHB. Hence, GDM had a greater impact on birthweight in NHB infants than in NHW infants (61 $\mathrm{g}$ racial difference [95\% CI $40,81]$ ), while prepregnancy diabetes had a large but similar effect on NHW and NHB infants (non-statistically significant $2 \mathrm{~g}$ racial difference). Further adjustment for maternal BMI at delivery slightly attenuated the racial difference associated with GDM (51 g [95\% CI 31, 72]); however, further adjustment for maternal tobacco use, hypertension, education and prenatal care as well as whether an infant was firstborn had little effect on racial differences (Table 2, Models 2 and 3 , respectively).

Looking at BMI, we found that in NHW and NHB women, as maternal BMI increased at delivery, the impact of GDM and prepregnancy diabetes on infant birthweight 
Table 1 Maternal characteristics ${ }^{\mathrm{a}}$ ( $\%$ or mean) stratified by race and diabetes status during pregnancy for singleton live births of at least 28 weeks' gestation in South Carolina 2004-2006

Missing data: mother's age, $n=$ 5; BMI, $n=3,672$; delivery BMI, $n=4,200$; firstborn, $n=39$; hypertension, $n=265$; tobacco use, $n=96$; HS education, $n=421$

${ }^{\mathrm{a}} \mathrm{CI}$ are not presented due to the large sample size and implied tightness of the intervals

${ }^{\mathrm{b}} \mathrm{BMI}$ at delivery was calculated using maternal weight at delivery

${ }^{\mathrm{c}}$ Prenatal care was defined according to the revised GINDEX as reported by Alexander et al. [27], which combines information from the birth certificate on the trimester when prenatal care was first received and the total number of prenatal visits

DM, diabetes; PPDM, prepregnancy diabetes

\begin{tabular}{|c|c|c|c|c|c|c|}
\hline \multirow[t]{2}{*}{ Characteristic } & \multicolumn{3}{|l|}{ NHW } & \multicolumn{3}{|l|}{ NHB } \\
\hline & $\begin{array}{l}\text { No DM } \\
n=125,678\end{array}$ & $\begin{array}{l}\text { GDM } \\
n=8,645\end{array}$ & $\begin{array}{l}\text { PPDM } \\
n=2,372\end{array}$ & $\begin{array}{l}\text { No DM } \\
n=73,175\end{array}$ & $\begin{array}{l}\text { GDM } \\
n=4,910\end{array}$ & $\begin{array}{l}\text { PPDM } \\
n=2,395\end{array}$ \\
\hline Age (years) & 27.0 & 29.6 & 28.8 & 24.4 & 27.6 & 28.2 \\
\hline$<18$ years $(\%)$ & 3.2 & 0.8 & 1.2 & 7.3 & 2.3 & 1.7 \\
\hline$\geq 35$ years $(\%)$ & 11.6 & 22.2 & 19.9 & 6.2 & 15.0 & 17.8 \\
\hline Prepregnancy BMI $\left(\mathrm{kg} / \mathrm{m}^{2}\right)$ & 25.8 & 29.6 & 31.0 & 28.4 & 32.3 & 34.7 \\
\hline $25-30 \mathrm{~kg} / \mathrm{m}^{2}(\%)$ & 24.0 & 24.3 & 23.1 & 26.5 & 23.9 & 19.1 \\
\hline$\geq 30 \mathrm{~kg} / \mathrm{m}^{2}(\%)$ & 21.3 & 42.2 & 50.3 & 35.3 & 56.7 & 67.6 \\
\hline Delivery BMI ${ }^{\mathrm{b}}\left(\mathrm{kg} / \mathrm{m}^{2}\right)$ & 30.9 & 33.9 & 35.6 & 32.5 & 36.5 & 38.4 \\
\hline $30-35 \mathrm{~kg} / \mathrm{m}^{2}(\%)$ & 27.1 & 27.1 & 26.7 & 26.7 & 27.0 & 22.0 \\
\hline$\geq 35 \mathrm{~kg} / \mathrm{m}^{2}(\%)$ & 21.6 & 39.3 & 47.4 & 31.3 & 52.2 & 62.7 \\
\hline Medicaid (\%) & 40.7 & 37.0 & 57.2 & 72.9 & 72.8 & 85.1 \\
\hline State Health Plan (\%) & 7.9 & 10.4 & 11.8 & 3.7 & 6.0 & 6.9 \\
\hline Private insurance (\%) & 51.4 & 57.4 & 43.6 & 21.0 & 28.2 & 21.8 \\
\hline First born $(\%)$ & 44.2 & 37.9 & 38.8 & 40.2 & 34.5 & 31.5 \\
\hline Hypertension (\%) & 6.5 & 14.6 & 18.6 & 7.9 & 18.1 & 28.3 \\
\hline Tobacco use (\%) & 18.0 & 16.6 & 21.7 & 8.2 & 7.8 & 8.0 \\
\hline High school education (\%) & 84.2 & 88.6 & 84.9 & 73.4 & 83.0 & 79.3 \\
\hline \multicolumn{7}{|l|}{ Prenatal care $^{\mathrm{c}}(\%)$} \\
\hline Intensive utilisation & 11.8 & 22.0 & 33.3 & 14.4 & 26.0 & 37.3 \\
\hline Adequate utilisation & 41.2 & 43.4 & 36.2 & 33.2 & 37.0 & 29.9 \\
\hline Intermediate utilisation & 37.5 & 27.7 & 23.4 & 37.0 & 28.3 & 22.9 \\
\hline Inadequate utilisation & 8.4 & 6.2 & 6.2 & 13.56 & 7.8 & 8.6 \\
\hline No care & 0.7 & 0.7 & 0.8 & 0.8 & 0.7 & 0.9 \\
\hline Missing required data & 0.5 & 0.2 & 0.1 & 1.1 & 0.3 & 0.4 \\
\hline
\end{tabular}

increased (Fig. 2). Birthweight was higher in women with GDM than in women without diabetes at a delivery BMI of $\geq 34 \mathrm{~kg} / \mathrm{m}^{2}$ in NHW and at a delivery BMI of $\geq 28 \mathrm{~kg} / \mathrm{m}^{2}$ in NHB. Birthweight was higher in women with prepregnancy diabetes than in women without diabetes when delivery BMI reached $\geq 26 \mathrm{~kg} / \mathrm{m}^{2}$ in NHW and when delivery BMI reached $\geq 29 \mathrm{~kg} / \mathrm{m}^{2}$ in NHB. The impact of diabetes on birthweight was significantly greater in NHB than in NHW when delivery BMI reached $\geq 28 \mathrm{~kg} / \mathrm{m}^{2}$ for GDM, but was similar in NHB and NHW women with prepregnancy diabetes. At a delivery BMI of $35 \mathrm{~kg} / \mathrm{m}^{2}$, exposure to GDM was associated with an average birthweight $17 \mathrm{~g}$ (95\% CI 4, 30) higher in NHW and $78 \mathrm{~g}(95 \%$ CI 61, 95) higher in NHB after controlling for gestational age, maternal age, infant sex and availability of prenatal care information (Table 3, Model 1). Parallel numbers for prepregnancy diabetes were $58 \mathrm{~g} \mathrm{(95 \%} \mathrm{CI}$ $34,81)$ in NHW and $60 \mathrm{~g}(95 \% \mathrm{CI} 37,84)$ in NHB. Hence, GDM had a greater impact on birthweight in NHB infants than in NHW infants (60 g racial difference [95\% CI 39, 82]), while prepregnancy diabetes had a large but similar effect on NHW and NHB infants (non-statistically significant $3 \mathrm{~g}$ racial difference). Further adjustment for maternal tobacco use, hypertension, education and prenatal care as well as whether an infant was firstborn had little effect on racial differences for either GDM or prepregnancy diabetes (Table 3, Model 2).

The prevalence of having an LGA infant was highest in women with prepregnancy diabetes (NHW, 19.3\%; NHB, $12.1 \%$ ) and lowest in women without diabetes (NHW, 9.2\%; NHB, 3.8\%; Table 4). After adjusting for demographic factors (maternal age, infant sex) and the availability of prenatal diagnostic codes, the risk of having an LGA infant relative to an infant with normal weight for gestational age (NGA) associated with GDM was $41 \%$ higher in NHW (RR 1.41 [95\% CI 1.34, 1.49]) and 124\% higher in NHB (RR 2.24 [95\% CI 2.05, 2.46]), while the risk associated with prepregnancy diabetes was $102 \%$ higher in NHW (RR 2.02 [95\% CI 1.86, 2.19]) and 180\% higher in NHB (RR 2.80 [95\% CI 2.50, 3.14]; Table 5). Additional adjustment for maternal BMI at delivery attenuated the RRs associated with having an LGA infant somewhat; however, adjusting for maternal education level, Medicaid status and pregnancy risk factors (firstborn, tobacco use, diabetes status and hypertension status, as well as prenatal care as defined by the revised GINDEX) did not further attenuate the increased risk associated with GDM or prepregnancy diabetes of having an LGA infant in NHW or NHB women. When the 
Fig. 1 Gestational age-specific birthweight curves stratified by diabetes status (left axis) paired with a histogram of per cent of births by gestational age (right axis) in NHW (a) and NHB (b) women. White symbols, NHW; black symbols; NHB; squares, no diabetes; triangles, GDM; circles, prepregnancy diabetes. The single model used to obtain birthweight curves for both panels $\mathbf{a}$ and $\mathbf{b}$ was adjusted for maternal age, infant sex, an index variable for the availability of prenatal diagnostic codes, race, diabetes status, four terms for gestational age (linear, quadratic, cubic and fourth-order polynomial term), and appropriate interaction terms between race, diabetes status and the four gestational age terms. Data at a gestational age of 38 and 40 weeks are presented in Model 1 of Table 2

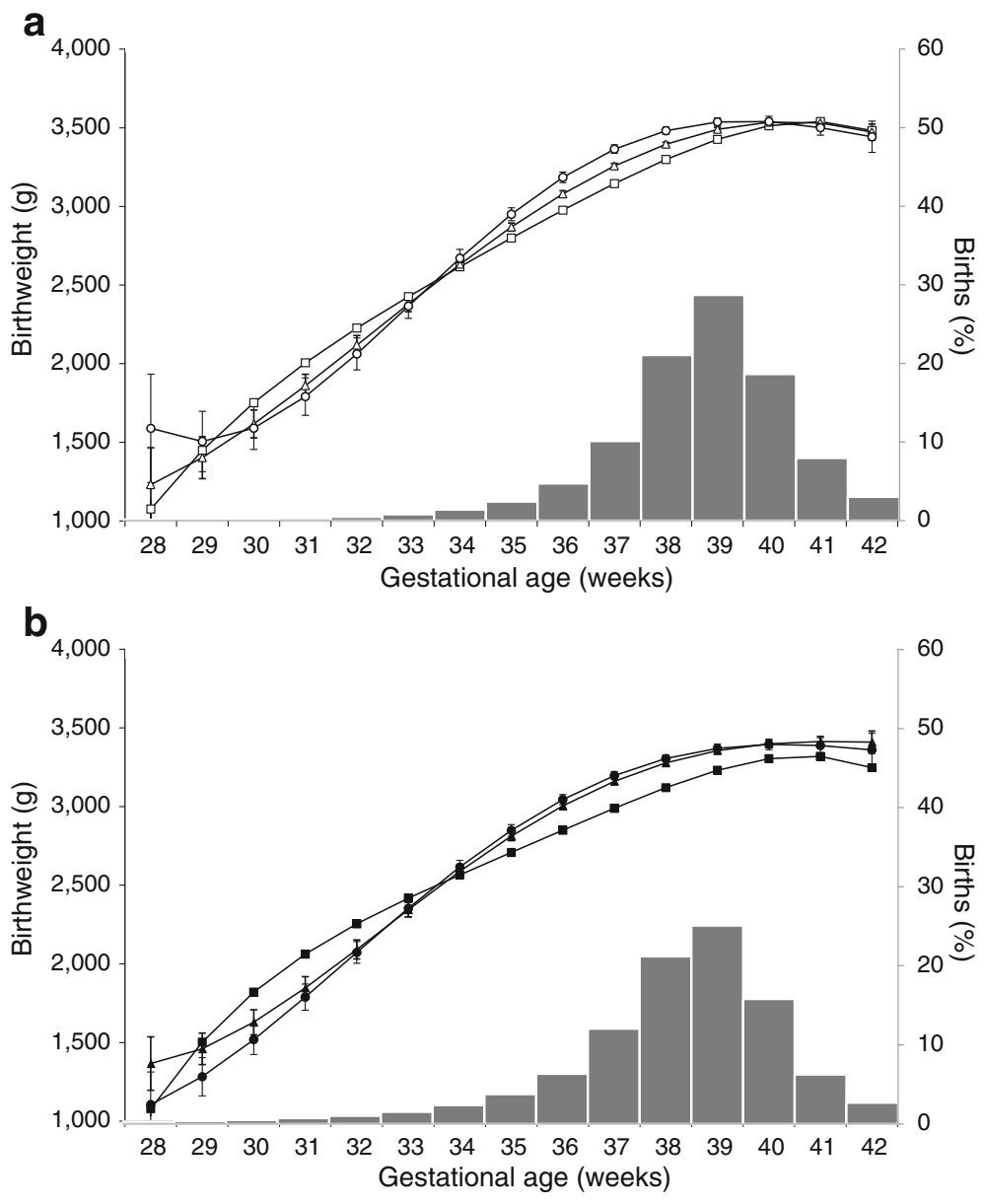

outcome was SGA, the risk associated with GDM and prepregnancy diabetes was marginal in NHW and NHB women (Table 5).

\section{Discussion}

In the majority of births to NHW and NHB women, GDM, prepregnancy diabetes and obesity were associated with increased fetal growth as measured by birthweight. Moreover, while the impact of GDM on birthweight was greater in NHB than in NHW, the impact of prepregnancy diabetes was similar in NHB and NHW for the majority of births. Interestingly, in NHW women prepregnancy diabetes had a greater impact on infant birthweight than did GDM, while in NHB women prepregnancy diabetes and GDM had a similar impact on infant birthweight. In NHW infants GDM did not have a statistically significant impact on infant birthweight until maternal delivery BMI reached $34 \mathrm{~kg} / \mathrm{m}^{2}$. By contrast, in NHB women GDM impacted infant birthweight at a maternal delivery BMI of $28 \mathrm{~kg} / \mathrm{m}^{2}$. As maternal BMI at delivery increased, the differential impact of GDM on birthweight between NHW and NHB infants increased, while the impact of prepregnancy diabetes on birthweight was similar in NHW and NHB infants across the spectrum of maternal BMI.

Our results are consistent with recent results from the Hyperglycemia and Adverse Pregnancy Outcome (HAPO) study which reported that hyperglycaemia below levels diagnostic of GDM [33] and maternal BMI at the time of the OGTT $[34,35]$ were each independently and positively associated with birthweight $>90$ th percentile, with the association for each exposure being continuous and graded. While the HAPO study did not find evidence of interaction between maternal BMI at the time of the OGTT and glycaemia in relation to birthweight $>90$ th percentile [33], the investigators' analysis and a priori focus was not to examine whether maternal BMI modified the relationship between hyperglycaemia and birthweight; hence, their analysis, which used categorical variables for BMI, hyperglycaemia and the birthweight outcome, was not optimal to identify an interaction. Moreover, the magnitude of the racial difference of the impact of GDM on infant birthweight in our study, which was $60 \mathrm{~g}$ (95\% CI 39, 82) at a maternal BMI at delivery of $35 \mathrm{~kg} / \mathrm{m}^{2}$ and $90 \mathrm{~g}(95 \%$ CI 59,121$)$ at a maternal BMI at delivery of $45 \mathrm{~kg} / \mathrm{m}^{2}$, was of similar magnitude to results from recent randomised 
Table 2 Adjusted birthweights (g) and birthweight differences $(95 \% \mathrm{CI})$ at a gestational age of 38 and 40 weeks, stratified by race and diabetes status

${ }^{\mathrm{a}}$ Model 1 is specified in Fig. $1 \mathrm{a}, \mathrm{b}$

${ }^{\mathrm{b}}$ Model 2 additionally adjusts Model 1 for BMI at delivery as a polynomial modelled with three terms (linear, quadratic and cubic)

${ }^{\mathrm{c}}$ Model 3 additionally adjusts Model 2 for firstborn as well as maternal tobacco use, hypertension status, education and prenatal care as defined by the revised GINDEX

DM, diabetes; GA, gestational age; PPDM, prepregnancy diabetes

\begin{tabular}{|c|c|c|c|c|c|c|c|}
\hline Model & No DM & GDM & PPDM & $\pm \mathrm{GDM}$ & $\pm \mathrm{PPDM}$ & $\begin{array}{l} \pm \text { GDM } \\
\pm \text { Race }\end{array}$ & $\begin{array}{l} \pm \text { PPDM } \\
\pm \text { Race }\end{array}$ \\
\hline \multicolumn{8}{|l|}{ NHW } \\
\hline \multicolumn{8}{|l|}{ Model $1^{\mathrm{a}}$} \\
\hline GA 38 weeks & 3,299 & 3,396 & 3,482 & $97(84,109)$ & $183(160,205)$ & - & - \\
\hline GA 40 weeks & 3,513 & 3,536 & 3,539 & $23(6,39)$ & $27(-7,60)$ & - & - \\
\hline \multicolumn{8}{|l|}{ Model $2^{b}$} \\
\hline GA 38 weeks & 3,343 & 3,404 & 3,474 & $61(48,73)$ & $131(108,153)$ & - & - \\
\hline GA 40 weeks & 3,550 & 3,545 & 3,535 & $-5(-22,11)$ & $-15(-48,18)$ & - & - \\
\hline \multicolumn{8}{|l|}{ Model $3^{\mathrm{c}}$} \\
\hline GA 38 weeks & 3,404 & 3,475 & 3,553 & $71(59,83)$ & $150(128,172)$ & - & - \\
\hline GA 40 weeks & 3,613 & 3,615 & 3,607 & $2(-14,18)$ & $-6(-39,26)$ & - & - \\
\hline \multicolumn{8}{|l|}{ NHB } \\
\hline \multicolumn{8}{|l|}{ Model $1^{\mathrm{a}}$} \\
\hline GA 38 weeks & 3,120 & 3,278 & 3,305 & $157(141,174)$ & $185(162,208)$ & $61(40,81)$ & $2(-30,35)$ \\
\hline GA 40 weeks & 3,305 & 3,398 & 3,595 & $94(71,116)$ & $90(56,124)$ & $71(43,99)$ & $64(16,112)$ \\
\hline \multicolumn{8}{|l|}{ Model $2^{\mathrm{b}}$} \\
\hline GA 38 weeks & 3,144 & 3,256 & 3,272 & $112(96,128)$ & $128(105,151)$ & $51(31,72)$ & $-3(-35,29)$ \\
\hline GA 40 weeks & 3,316 & 3,379 & 3,357 & $62(40,85)$ & $41(7,75)$ & $68(40,95)$ & $56(9,103)$ \\
\hline \multicolumn{8}{|l|}{ Model $3^{c}$} \\
\hline GA 38 weeks & 3,180 & 3,304 & 3,333 & $125(109,141)$ & $153(130,176)$ & $53(33,73)$ & $3(-29,35)$ \\
\hline GA 40 weeks & 3,354 & 3,425 & 3,414 & $71(49,93)$ & $60(27,93)$ & $69(42,96)$ & $67(20,113)$ \\
\hline
\end{tabular}

intervention studies which suggest that treatment of mild GDM can reduce birthweight by 100-140 g [36, 37].

Strengths of previous relevant clinical studies include accurate ascertainment of maternal diabetes status and detailed information on patient characteristics [38-41]. In 2004 the
South Carolina birth certificate was revised to improve the quality of data collected relating to maternal diabetes and obesity. Specifically, check boxes were added to differentiate between gestational and established diabetes; and information on maternal height, prepregnancy weight and weight at delivery

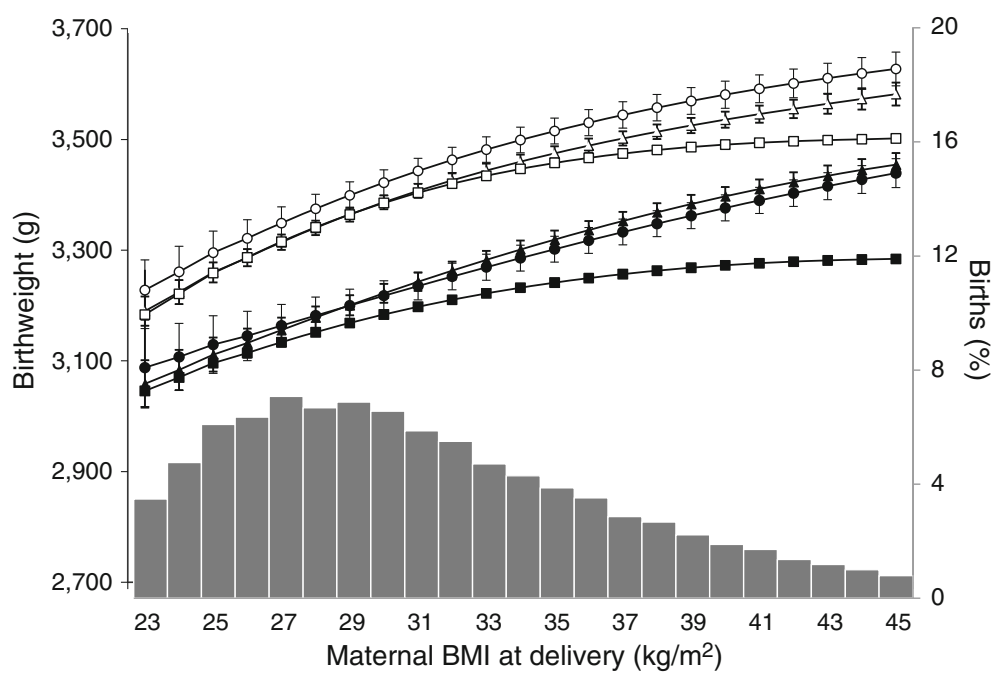

Fig. 2 Birthweight curves specific to maternal BMI at delivery stratified by maternal race and diabetes status. The figure contains the birthweight curves stratified by maternal race and diabetes status (left axis) and the histogram for per cent of births by maternal BMI at delivery (right axis). White symbols, NHW; black symbols; NHB; squares, no diabetes; triangles, GDM; circles, prepregnancy diabetes. The model used included maternal age, infant sex, an index variable for the availability of prenatal diagnostic codes, race, diabetes status, four terms for gestational age (linear, quadratic, cubic and fourth-order polynomial term), three terms for maternal BMI at delivery (linear, quadratic and cubic polynomial term), and appropriate interaction terms between race, diabetes status and BMI at delivery. Data at a maternal delivery BMI of 25, 35 and $45 \mathrm{~kg} / \mathrm{m}^{2}$ are presented in Model 1 of Table 3 
Table 3 Adjusted birthweights (g) and birthweight differences (with 95\% CI) at BMI 25, 35 and $45 \mathrm{~kg} / \mathrm{m}^{2}$ at delivery, stratified by race and diabetes status
${ }^{a}$ Model 1 is specified in Fig. 2

${ }^{\mathrm{b}}$ Model 2 additionally adjusts Model 1 for firstborn as well as maternal tobacco use, hypertension status, education and prenatal care as defined by the revised GINDEX

DM, diabetes; PPDM, prepregnancy diabetes

\begin{tabular}{|c|c|c|c|c|c|c|c|}
\hline Model & No DM & GDM & PPDM & $\pm \mathrm{GDM}$ & $\pm \mathrm{PPDM}$ & \pm GDM \pm Race & $\begin{array}{l} \pm \text { PPDM } \\
\pm \text { Race }\end{array}$ \\
\hline \multicolumn{8}{|l|}{ NHW } \\
\hline \multicolumn{8}{|l|}{ Model $1^{\mathrm{a}}$} \\
\hline BMI $25 \mathrm{~kg} / \mathrm{m}^{2}$ & 3,259 & 3,260 & 3,295 & $1(-17,19)$ & $37(-3,76)$ & - & - \\
\hline BMI $35 \mathrm{~kg} / \mathrm{m}^{2}$ & 3,458 & 3,475 & 3,515 & $17(4,30)$ & $58(34,81)$ & - & - \\
\hline BMI $45 \mathrm{~kg} / \mathrm{m}^{2}$ & 3,502 & 3,582 & 3,627 & $80(58,102)$ & $126(94,157)$ & - & - \\
\hline \multicolumn{8}{|l|}{ Model $2^{\mathrm{b}}$} \\
\hline BMI $25 \mathrm{~kg} / \mathrm{m}^{2}$ & 3,317 & 3,322 & 3,365 & $5(-13,23)$ & $47(9,86)$ & - & - \\
\hline BMI $35 \mathrm{~kg} / \mathrm{m}^{2}$ & 3,521 & 3,551 & 3,599 & $30(17,43)$ & $78(55,101)$ & - & - \\
\hline BMI $45 \mathrm{~kg} / \mathrm{m}^{2}$ & 3,581 & 3,671 & 3,726 & $90(69,112)$ & $146(115,177)$ & - & - \\
\hline \multicolumn{8}{|l|}{ NHB } \\
\hline \multicolumn{8}{|l|}{ Model $1^{\mathrm{a}}$} \\
\hline BMI $25 \mathrm{~kg} / \mathrm{m}^{2}$ & 3,096 & 3,111 & 3,129 & $15(-16,46)$ & $33(-19,86)$ & $14(-22,50)$ & $-3(-69,62)$ \\
\hline BMI $35 \mathrm{~kg} / \mathrm{m}^{2}$ & 3,241 & 3,319 & 3,302 & $78(61,95)$ & $60(37,84)$ & $60(39,82)$ & $3(-31,36)$ \\
\hline BMI $45 \mathrm{~kg} / \mathrm{m}^{2}$ & 3,284 & 3,455 & 3,439 & $170(148,193)$ & $155(128,182)$ & $90(59,121)$ & $29(-12,71)$ \\
\hline \multicolumn{8}{|l|}{ Model $2^{b}$} \\
\hline BMI $25 \mathrm{~kg} / \mathrm{m}^{2}$ & 3,128 & 3,147 & 3,178 & $19(-12,50)$ & $50(-2,101)$ & $14(-22,50)$ & $2(-62,67)$ \\
\hline BMI $35 \mathrm{~kg} / \mathrm{m}^{2}$ & 3,278 & 3,370 & 3,364 & $93(76,109)$ & $86(62,109)$ & $62(41,83)$ & $8(-25,41)$ \\
\hline BMI $45 \mathrm{~kg} / \mathrm{m}^{2}$ & 3,333 & 3,523 & 3,521 & $191(167,213)$ & $188(161,215)$ & $100(69,131)$ & $42(1,83)$ \\
\hline
\end{tabular}

was added. Moreover, a validation study was conducted on a population-based sample of 4,541 women who had live births in 2000 in Washington State, which uses a birth certificate comparable to the South Carolina birth certificate [42]. The reported true-positive fraction combining information across the birth certificate with hospital discharge data and using medical record review as the gold standard was 93.3 (95\% CI 86.9, 99.7) for GDM and 96.9 (95\% CI 91.6, 100) for established diabetes in the validation study [42]. Respective false-positive fractions were 0.9 (95\% CI $0.5,1.4)$ and 0.5 (95\% CI 0, 1.1) [42].

In the current study, diagnostic codes were available during the prenatal period for $58.5 \%$ of births. Among individuals receiving prenatal care through Medicaid, the prevalence of any type of diabetes during pregnancy was
$7.2 \%$ based on the Washington State diabetes criteria and increased to $8.4 \%$ when information from prenatal care was incorporated which required at least two diagnostic codes indicative of diabetes for a positive diabetes classification. The Washington State validation study indicated that combining information across multiple sources provided the best definition of diabetes during pregnancy [42]; hence, we opted to be inclusive in our definition of diabetes during pregnancy.

The prevalence of identified diabetes during pregnancy of $9.1 \%$ in NHB and $8.1 \%$ in NHW are on the high end of current estimates of diabetes during pregnancy, which range from $2 \%$ to $10 \%$ of pregnancies in the United States, with estimates being higher for racial and ethnic minority groups than for NHW groups [43]. Notably, the prevalence of

Table 4 Infant characteristics (\% or mean), stratified by race and diabetes status during pregnancy for singleton live births in South Carolina 2004-2008

\begin{tabular}{|c|c|c|c|c|c|c|}
\hline \multirow[t]{2}{*}{ Characteristic } & \multicolumn{3}{|l|}{ NHW } & \multicolumn{3}{|l|}{ NHB } \\
\hline & $\begin{array}{l}\text { No DM } \\
n=125,678\end{array}$ & $\begin{array}{l}\text { GDM } \\
n=8,645\end{array}$ & $\begin{array}{l}\text { PPDM } \\
n=2,372\end{array}$ & $\begin{array}{l}\text { No DM } \\
n=73,175\end{array}$ & $\begin{array}{l}\text { GDM } \\
n=4,910\end{array}$ & $\begin{array}{l}\text { PPDM } \\
n=2,395\end{array}$ \\
\hline Female infant $(\%)$ & 48.7 & 46.7 & 46.3 & 49.4 & 49.3 & 49.0 \\
\hline Gestational age (weeks) & 38.6 & 38.3 & 37.9 & 38.1 & 37.9 & 37.5 \\
\hline Gestational age $\geq 37$ weeks & 89.8 & 87.3 & 80.9 & 83.5 & 80.8 & 74.8 \\
\hline LGA, $>90$ th percentile & 9.2 & 14.1 & 19.3 & 3.8 & 9.9 & 12.1 \\
\hline SGA, $<10$ th percentile & 9.5 & 8.4 & 9.2 & 19.1 & 14.1 & 17.0 \\
\hline
\end{tabular}

$\mathrm{CI}$ are not presented due to the large sample size and implied tightness of the intervals

DM, diabetes; LGA, large for gestational age; PPDM, prepregnancy diabetes; SGA, small for gestational age 
Table 5 Adjusted RRs (and 95\% CI) for GDM and prepregnancy diabetes during pregnancy relative to women without diabetes in relation to having LGA or SGA infants for singleton live births in South Carolina 2004-2008

\begin{tabular}{|c|c|c|c|c|}
\hline \multirow[t]{2}{*}{ Model/outcome } & \multicolumn{2}{|l|}{ GDM } & \multicolumn{2}{|c|}{ Prepregnancy diabetes } \\
\hline & NHW & NHB & NHW & NHB \\
\hline \multicolumn{5}{|l|}{ Models 1 and $2^{\mathrm{a}}$} \\
\hline LGA vs NGA & $1.41(1.34,1.49)$ & $2.24(2.05,2.46)$ & $2.02(1.86,2.19)$ & $2.80(2.50,3.14)$ \\
\hline SGA vs NGA & $0.99(0.92,1.06)$ & $0.83(0.78,0.89)$ & $1.07(0.94,1.21)$ & $1.01(0.92,1.11)$ \\
\hline \multicolumn{5}{|l|}{ Models 3 and $4^{\mathrm{b}}$} \\
\hline LGA vs NGA & $1.20(1.13,1.26)$ & $1.87(1.71,2.05)$ & $1.55(1.42,1.69)$ & $2.10(1.87,2.35)$ \\
\hline SGA vs NGA & $1.05(1.04,1.35)$ & $0.92(0.86,0.99)$ & $1.08(1.03,1.14)$ & $1.17(1.07,1.28)$ \\
\hline \multicolumn{5}{|l|}{ Models 5 and $6^{\mathrm{c}}$} \\
\hline LGA vs NGA & $1.21(1.15,1.29)$ & $1.94(1.77,2.13)$ & $1.61(1.48,1.76)$ & $2.22(1.98,2.49)$ \\
\hline SGA vs NGA & $1.02(0.97,1.25)$ & $0.89(0.83,0.95)$ & $1.10(0.97,1.25)$ & $1.06(0.97,1.16)$ \\
\hline
\end{tabular}

${ }^{a}$ Models 1 and 2 included maternal age, infant sex, an index variable for whether or not prenatal diagnostic codes were available, race, two index variables to define the three levels of maternal diabetes status (no diabetes, GDM and prepregnancy diabetes), and interaction terms between race and the two index variables defining diabetes status

${ }^{\mathrm{b}}$ Models 3 and 4 additionally included a linear term for maternal BMI at delivery

${ }^{\mathrm{c}}$ Models 5 and 6 additionally adjusted models 3 and 4 for firstborn as well as maternal tobacco use, hypertension status, education and prenatal care as defined by the revised GINDEX

In models 1,3 and 5 the $p$ values for interaction between NHW and NHB were $<0.0001$ for GDM as well as for prepregnancy diabetes. In models 2 , 4 , and 6 the $p$ values for interaction between NHW and NHB were $<0.01$ for GDM but were not significant for prepregnancy diabetes $(0.5194$, 0.8867 and 0.6073 , respectively)

identified diabetes during pregnancy in the current study is considerably higher than that reported in the national population-based study using data on live births from 1990 to 1991, which reported a prevalence of diabetes during pregnancy of $2.26 \%$ in NHB and $1.98 \%$ in NHW [25].

Prior population-based studies of racial disparities of the impact of diabetes on birthweight have not incorporated information on maternal weight or type of diabetes (i.e. prepregnancy or gestational). Moreover, maternal weight and maternal weight gain are associated with increased birthweight [44, 45]. Hence, we sought to examine the extent to which obesity modified the effect of diabetes on birthweight. We focused on maternal BMI at delivery because it incorporated information on maternal prepregnancy weight as well as maternal weight gain during pregnancy. The quality of data on diabetes status, which includes the subdivision by GDM or prepregnancy diabetes, is impacted not only by reporting, coding and screening practices (both before and during pregnancy) but also by whether or not we had information on prenatal care from either the State Health Plan or Medicaid, all of which may be differential with respect to race. In our study, use of Medicaid was higher in NHB (73.3\%) than in NHW (40.8\%); hence, ascertainment of diabetes during pregnancy may be more complete in NHB than in NHW. On the other hand, because Medicaid eligibility is dependent on need, and eligibility increases during pregnancy, individuals with private insurance may receive better care prior to pregnancy. Moreover, screening, diagnosis and treatment practices for diabetes during pregnancy likely varied across the state from one doctor's office to another. In this study the prevalence of prepregnancy diabetes $(3.0 \%$ vs $1.7 \%)$ was higher in NHB than in NHW women, while the prevalence of GDM was similar in NHW and NHB women (6.3 vs 6.1\%). We elected to classify individuals as having prepregnancy diabetes rather than GDM if information from any source reported prepregnancy diabetes. As a result, $41.5 \%$ of NHB women and $44.5 \%$ of NHW women with a classification of prepregnancy diabetes also had GDM reported on their birth certificate, hospital discharge record or prenatal record. Our prevalence estimates for prepregnancy diabetes and GDM are consistent with results from a study of the Kaiser Permanente managed healthcare programme in Southern California which reports 2005 prevalence estimates for prepregnancy diabetes of $1.5 \%$ in NHW and $2.6 \%$ in NHB, and prevalence estimates for GDM of 5.3\% in NHW and 5.0\% in NHB [46].

Type of diabetes may be important because women with prepregnancy diabetes are at risk of adverse pregnancy outcomes starting in the periconceptional period, while risks associated with GDM usually develop in the second trimester. Among those with diabetes the prevalence of prepregnancy diabetes was higher in NHB than in NHW (32.8\% vs $21.5 \%$ ). Interestingly, the impact of prepregnancy diabetes on infant birthweight appears similar in NHW and NHB women. However, in NHB women, infant birthweight is similar in those with GDM or prepregnancy diabetes; while in NHW women, infant birthweight is higher in those with prepregnancy 
diabetes than in those with GDM, resulting in a differential impact of GDM on birthweight by race. Potential explanations for these findings are that a higher percentage of NHB women with GDM than NHW women with GDM actually had undiagnosed diabetes prior to pregnancy, that diabetes with onset during pregnancy is actually more severe in NHB than in NHW women, or that treatment (or response to treatment) for GDM is poorer in NHB than in NHW women. The prevalence of intensive prenatal care as defined by the revised GINDEX was higher in NHB women with GDM (26.0\%) than in NHW women with GDM (22.0\%). However, NHW women with GDM were much more likely to report private health insurance than were NHB women with GDM (57.4\% vs $28.2 \%$, respectively), which may indicate more comprehensive healthcare prior to pregnancy in NHW than in NHB women. A surveillance study of diabetes in youth estimated the prevalence of type 1 diabetes to be lower and the prevalence of type 2 diabetes to be higher in NHB teenagers than in NHW teenagers [47].

One study limitation is that we did not have information on treatment received for diabetes during pregnancy - an important factor because tight control of glucose levels during pregnancy impacts infant birthweight [36, 37]. A second limitation of our study is the use of administrative databases and the reliability of data obtained from these databases. For instance, the quality of data available differentiating between prepregnancy and GDM, as well as our inability to discriminate between type 1 and type 2 diabetes, prevented us from completing an exhaustive analysis of the impact of diabetes type on racial differences in outcomes. Hence, differential diagnosis, treatment and severity of diabetes during pregnancy may be explanations for the greater impact of GDM on birthweight in NHB relative to NHW which we were unable to assess. Finally, the use of LMP to calculate gestational age has limitations [48] which may be differential with respect to diabetes status, given the association between diabetes and irregular menses [49, 50]; however, because birthweight, our outcome, may differentially impact the clinical/obstetric estimate of gestational age we relied on LMP to calculate gestational age.

Our study provides evidence that GDM has a greater impact on birthweight in NHB infants than in NHW infants, and that this disparity increases with increasing maternal BMI. In NHW infants, GDM appears only to impact birthweight when maternal delivery BMI is $\geq 34 \mathrm{~kg} / \mathrm{m}^{2}$, which is relatively high. By contrast, in NHB infants, GDM appears to impact birthweight starting at a much lower maternal delivery BMI of $28 \mathrm{~kg} / \mathrm{m}^{2}$. Interestingly, for the vast majority of births, prepregnancy diabetes appears to have a similar impact on birthweight in NHB and NHW infants. Because the prevalence of diabetes is quite high in our study ( $9.1 \%$ in NHB and $8.1 \%$ in NHW), even a small shift in birthweight is likely to have a large impact at the population level. Further research is warranted to understand the impact of maternal diabetes and obesity during pregnancy on racial health disparities.

Funding This work was supported by a grant from the National Institute on Minority Health and Health Disparities (R01-MD004251). The funding agency did not participate in the design and conduct of the study; collection, management, analysis and interpretation of the data; and preparation, review or approval of the article.

Contribution statement $\mathrm{KJH}, \mathrm{JM}, \mathrm{MEM}$, and JEK contributed to the study concept and design; $\mathrm{KJH}$ acquired the data; $\mathrm{KJH}, \mathrm{NMM}, \mathrm{MG}$ and CNE performed statistical analysis and interpreted the data; $\mathrm{KJH}$, CNE and JEK drafted the manuscript; NMM, MG, JM, MEM and JEK reviewed the manuscript for important intellectual content; $\mathrm{KJH}$ and MEM obtained funding; KJH and MEM supervised the study; KJH, NMM, MG, CNE, JM, MEM and JEK approved the final manuscript version to be published.

Duality of interest statement The authors declare that there is no duality of interest associated with this manuscript.

\section{References}

1. Burke JP, Williams K, Gaskill SP, Hazuda HP, Haffner SM, Stern MP (1999) Rapid rise in the incidence of type 2 diabetes from 1987 to 1996: results from the San Antonio Heart Study. Arch Intern Med 159:1450-1456

2. Dabelea D, Pettitt DJ, Jones KL, Arslanian SA (1999) Type 2 diabetes mellitus in minority children and adolescents. An emerging problem. Endocrinol Metab Clin North Am 28:709-729, viii

3. Fagot-Campagna A, Pettitt DJ, Engelgau MM et al (2000) Type 2 diabetes among North American children and adolescents: an epidemiologic review and a public health perspective. J Pediatr 136:664-672

4. Fagot-Campagna A, Saaddine JB, Flegal KM, Beckles GL (2001) Diabetes, impaired fasting glucose, and elevated $\mathrm{HbA}_{1 \mathrm{c}}$ in U.S. adolescents: the Third National Health and Nutrition Examination Survey. Diabetes Care 24:834-837

5. Harris MI, Flegal KM, Cowie CC et al (1998) Prevalence of diabetes, impaired fasting glucose, and impaired glucose tolerance in U.S. adults. The Third National Health and Nutrition Examination Survey, 1988-1994. Diabetes Care 21:518-524

6. Rosenbloom AL, Joe JR, Young RS, Winter WE (1999) Emerging epidemic of type 2 diabetes in youth. Diabetes Care 22:345-354

7. Cowie CC, Rust KF, Byrd-Holt DD et al (2006) Prevalence of diabetes and impaired fasting glucose in adults in the U.S. population: National Health and Nutrition Examination Survey 1999-2002. Diabetes Care 29:1263-1268

8. Narayan KM, Boyle JP, Thompson TJ, Sorensen SW, Williamson DF (2003) Lifetime risk for diabetes mellitus in the United States. JAMA 290:1884-1890

9. Barker DJ (1995) Fetal origins of coronary heart disease. BMJ 311:171-174

10. Berkowitz GS, Lapinski RH, Wein R, Lee D (1992) Race/ethnicity and other risk factors for gestational diabetes. Am J Epidemiol 135:965-973

11. Solomon CG, Willett WC, Carey VJ et al (1997) A prospective study of pregravid determinants of gestational diabetes mellitus. JAMA 278:1078-1083 
12. Zhang S, Folsom AR, Flack JM, Liu K (1995) Body fat distribution before pregnancy and gestational diabetes: findings from Coronary Artery Risk Development In Young Adults (CARDIA) study. BMJ 311:1139-1140

13. Freinkel N (1980) Banting Lecture 1980. Of pregnancy and progeny. Diabetes 29:1023-1035

14. Silverman BL, Rizzo T, Green OC et al (1991) Long-term prospective evaluation of offspring of diabetic mothers. Diabetes 40 (Suppl 2):121-125

15. O'Sullivan JB, Gellis SS, Dandrow RV, Tenney BO (1966) The potential diabetic and her treatment in pregnancy. Obstet Gynecol 27:683-689

16. Pettitt DJ, Knowler WC, Baird HR, Bennett PH (1980) Gestational diabetes: infant and maternal complications of pregnancy in relation to third-trimester glucose tolerance in the Pima Indians. Diabetes Care 3:458-464

17. Pettitt DJ, Knowler WC (1998) Long-term effects of the intrauterine environment, birth weight, and breast-feeding in Pima Indians. Diabetes Care 21(Suppl 2):B138-B141

18. Pettitt DJ, Aleck KA, Baird HR, Carraher MJ, Bennett PH, Knowler WC (1988) Congenital susceptibility to NIDDM. Role of intrauterine environment. Diabetes 37:622-628

19. Hanson RL, Elston RC, Pettitt DJ, Bennett PH, Knowler WC (1995) Segregation analysis of non-insulin-dependent diabetes mellitus in Pima Indians: evidence for a major-gene effect. Am J Hum Genet 57:160-170

20. Nesbitt TS, Gilbert WM, Herrchen B (1998) Shoulder dystocia and associated risk factors with macrosomic infants born in California. Am J Obstet Gynecol 179:476-480

21. Jolly MC, Sebire NJ, Harris JP, Regan L, Robinson S (2003) Risk factors for macrosomia and its clinical consequences: a study of 350,311 pregnancies. Eur J Obstet Gynecol Reprod Biol 111:9-14

22. Alexander GR, Tompkins ME, Allen MC, Hulsey TC (1999) Trends and racial differences in birth weight and related survival. Matern Child Health J 3:71-79

23. Alexander GR, Wingate MS, Bader D, Kogan MD (2008) The increasing racial disparity in infant mortality rates: composition and contributors to recent US trends. Am J Obstet Gynecol 198:51. e1-9

24. Schempf A, Kroelinger C, Guyer B (2007) Rising infant mortality in Delaware: an examination of racial differences in secular trends. Matern Child Health J 11:475-483

25. Kieffer EC, Alexander GR, Kogan MD et al (1998) Influence of diabetes during pregnancy on gestational age-specific newborn weight among US black and US white infants. Am J Epidemiol 147:1053-1061

26. Miller DR, Safford MM, Pogach LM (2004) Who has diabetes? Best estimates of diabetes prevalence in the Department of Veterans Affairs based on computerized patient data. Diabetes Care 27 (Suppl 2):B10-B21

27. Alexander GR, Kotelchuck M (1996) Quantifying the adequacy of prenatal care: a comparison of indices. Public Health Rep 111:408-418

28. Alexander GR, Himes JH, Kaufman RB, Mor J, Kogan M (1996) A United States national reference for fetal growth. Obstet Gynecol 87:163-168

29. Oken E, Kleinman KP, Rich-Edwards J, Gillman MW (2003) A nearly continuous measure of birth weight for gestational age using a United States national reference. BMC Pediatr 3:6

30. Wacholder S (1986) Binomial regression in GLIM: estimating risk ratios and risk differences. Am J Epidemiol 123:174-184

31. Zou G (2004) A modified Poisson regression approach to prospective studies with binary data. Am J Epidemiol 159:702-706
32. Spiegelman D, Hertzmark E (2005) Easy SAS calculations for risk or prevalence ratios and differences. Am J Epidemiol 162:199-200

33. Metzger BE, Lowe LP, Dyer AR et al (2008) Hyperglycemia and adverse pregnancy outcomes. N Engl J Med 358:1991-2002

34. HAPO Study Cooperative Research Group (2010) Hyperglycaemia and Adverse Pregnancy Outcome (HAPO) Study: associations with maternal body mass index. BJOG 117:575-584

35. Froslie KF, Roislien J, Laake P, Henriksen T, Qvigstad E, Veierod MB (2010) Categorisation of continuous exposure variables revisited. A response to the Hyperglycaemia and Adverse Pregnancy Outcome (HAPO) Study. BMC Med Res Methodol 10:103

36. Crowther CA, Hiller JE, Moss JR, McPhee AJ, Jeffries WS, Robinson JS (2005) Effect of treatment of gestational diabetes mellitus on pregnancy outcomes. N Engl J Med 352:2477-2486

37. Landon MB, Spong CY, Thom E et al (2009) A multicenter, randomized trial of treatment for mild gestational diabetes. N Engl J Med 361:1339-1348

38. Goldenberg RL, Cliver SP, Mulvihill FX et al (1996) Medical, psychosocial, and behavioral risk factors do not explain the increased risk for low birth weight among black women. Am J Obstet Gynecol 175:1317-1324

39. Saldana TM, Siega-Riz AM, Adair LS, Savitz DA, Thorp JM Jr (2003) The association between impaired glucose tolerance and birth weight among black and white women in central North Carolina. Diabetes Care 26:656-661

40. Scholl TO, Chen X, Gaughan C, Smith WK (2002) Influence of maternal glucose level on ethnic differences in birth weight and pregnancy outcome. Am J Epidemiol 156:498-506

41. Singh KA, Huston-Presley LP, Mencin P, Thomas A, Amini SB, Catalano PM (2010) Birth weight and body composition of neonates born to Caucasian compared with African-American mothers. Obstet Gynecol 115:998-1002

42. Lydon-Rochelle MT, Holt VL, Cardenas Vet al (2005) The reporting of preexisting maternal medical conditions and complications of pregnancy on birth certificates and in hospital discharge data. Am J Obstet Gynecol 193:125-134

43. Hunt KJ, Schuller KL (2007) The increasing prevalence of diabetes in pregnancy. Obstet Gynecol Clin North Am 34: 173-199, vii

44. Ehrenberg HM, Mercer BM, Catalano PM (2004) The influence of obesity and diabetes on the prevalence of macrosomia. Am J Obstet Gynecol 191:964-968

45. Ludwig DS, Currie J (2010) The association between pregnancy weight gain and birthweight: a within-family comparison. Lancet 376:984-990

46. Lawrence JM, Contreras R, Chen W, Sacks DA (2008) Trends in the prevalence of preexisting diabetes and gestational diabetes mellitus among a racially/ethnically diverse population of pregnant women, 1999-2005. Diabetes Care 31:899-904

47. Liese AD, D'Agostino RB Jr, Hamman RF et al (2006) The burden of diabetes mellitus among US youth: prevalence estimates from the SEARCH for Diabetes in Youth Study. Pediatrics 118 $1510-1518$

48. Kramer MS, McLean FH, Boyd ME, Usher RH (1988) The validity of gestational age estimation by menstrual dating in term, preterm, and postterm gestations. JAMA 260:3306-3308

49. Gaete X, Vivanco M, Eyzaguirre FC et al (2010) Menstrual cycle irregularities and their relationship with $\mathrm{HbA}_{1 \mathrm{c}}$ and insulin dose in adolescents with type 1 diabetes mellitus. Fertil Steril 94: $1822-1826$

50. Strotmeyer ES, Steenkiste AR, Foley TP Jr, Berga SL, Dorman JS (2003) Menstrual cycle differences between women with type 1 diabetes and women without diabetes. Diabetes Care 26: $1016-1021$ 